\title{
Functional and Anatomic Correlates of two Frequently Observed Temporal Lobe Seizure-Onset Patterns
}

\author{
Ana Luisa Velasco ${ }^{1}$, Charles L. Wilson ${ }^{2,4}$, Thomas L. Babb ${ }^{5}$, Jerome Engel $\mathrm{Jr}^{2,3,4, \uparrow}$ \\ ${ }^{1}$ Medical Research Unit in Neurophysiology, National Medical Center, IMSS Mexico City, Mexico; \\ Departments of ${ }^{2}$ Neurology and ${ }^{3}$ Neurobiology and the ${ }^{4}$ Brain Research Institute, UCLA Center for the \\ Health Sciences, Los Angeles, CA 90095, USA; ${ }^{5}$ Department of Neurosciences NC-30 Cleveland Clinic \\ Foundation, 9500 Euclid Avenue, Cleveland, OH 44195, USA
}

\section{SUMMARY}

Intracranial depth electrode EEG records of 478 seizures, recorded in 68 patients undergoing diagnostic monitoring with depth electrodes, were evaluated to investigate the correlates of electrographic onset patterns in patients with temporal lobe seizures. The seizure onsets in $78 \%$ of these patients were identified as either hypersynchronous onsets, beginning with low-frequency, high-amplitude spikes, or low-voltage fast (LVF) onsets, increasing in amplitude as the seizure progressed. The number of patients (35) having hypersynchronous seizure onsets was nearly twice that of patients (18) having LVF onsets. Three major differences were seen among patients with the two seizure-onset patterns. When compared with patients having LVF onsets, patients with hypersynchronous seizure onsets had a significantly greater probability of having (1) focal rather than regional seizure onsets $(p<0.01)$, (2) seizures spreading more slowly to the contralateral mesial temporal lobe $(p<0.003)$, and $(3)$ cell counts in resected hippocampal tissue showing greater neuronal loss $(p<0.001)$. The results provide evidence that the most frequent

\footnotetext{
${ }^{\dagger}$ Corresponding author:

Tel: +1-310-825-5745

Fax: +1-310-206-8461

email: engel@ucla.edu
}

electrographic abnormality associated with mesial temporal seizures is local hypersynchrony, a condition associated with major neuronal loss in the hippocampus. The results also indicate that LVF seizure onsets more frequently represent widely distributed discharges, which interact with and spread more rapidly to surrounding neocortical areas.

\section{KEYWORDS}

epilepsy, hippocampus, hippocampal sclerosis, EEG, hypersynchrony

\section{INTRODUCTION}

Medically intractable complex partial seizures often have localized onsets in brain structures that can be surgically resected for seizure control without significant neurological deficits. The localization of seizures in the temporal lobe sometimes requires the use of intracranial depth electrodes to access the source of seizure onsets arising from deep in the mesial limbic areas. This requirement has provided an opportunity to study directly the patterns of ictal discharge that initiate such seizures (Engel et al., 1989). In addition, postoperative analysis of resected tissue has shown that most patients with temporal lobe epilepsy (TLE) have hippocampal sclerosis (HS), providing the opportunity to study the electrographic characteristics of seizures that are 
associated with HS (Babb et al., 1984; Babb \& Brown, 1987).

It is generally accepted that seizure onsets in HS-associated TLE arise from a background of low-frequency, high-amplitude periodic spiking, which is often followed by low-voltage fast (LVF) activity in the beta range (Spencer, 1999). Another common pattern of seizure onset begins with LVF activity or suppression of the EEG. We (Engel et al., 1989) contrasted this pattern with the hypersynchronous spiking onset pattern that we initially described as the most frequently encountered pattern in the mesial temporal lobe. Subsequently, many investigations of temporal lobe seizure-onset pattern have been published, including studies by Spencer et al. (1992a), Park et al. (1996), Spanneda et al. (1997), and Schiller et al. (1998).

The purpose of the present study was to review retrospectively a large number of seizures that had been recorded from temporal lobe depth electrodes in patients required for seizure localization for surgical treatment. The seizures were then categorized according to their onset patterns and correlated with measures of pathology and neuronal loss, focal or regional onset distribution, and rapid or slow spread to other structures.

\section{METHODS}

\section{Patients}

Data were collected retrospectively from 68 patients of the UCLA Seizure Disorders Center, who were being evaluated for surgical treatment of medically intractable complex partial seizures. Spontaneous seizure activity was monitored on a 24-h basis, employing stereotactically implanted depth electrodes for EEG recording of seizures and video telemetry for recording behavioral correlates of seizures. Monitoring was continued for 1 to 3 wk or until a sufficient number of seizures had been recorded for localization of the area of onset. The patients consisted of 36 males and 31 females, ranging in age from 15 to 49 . All patients sequentially completing the protocol for which records of seizure morphology and behavioral seizure correlates were available were included in the analysis. Only clinical seizures having behavioral as well as electrographic expression were used in the analysis. EEG recordings of seizures were scored by two encephalographers, who reached a consensus on the categorization of electrographic onset pattern. Mesial temporal pathology data was used from patients continuing to temporal lobe resection.

\section{Depth electrodes and recording sites}

EEG monitoring was carried out with 10 to 16 stereotactically placed flexible polyurethane electrodes (AD-Tech), which were introduced from a lateral aspect orthogonal to the sagittal plane of the temporal or frontal lobes. The electrodes had 7 platinum contacts, spaced at intervals of 3 to 6 $\mathrm{mm}$. After fixation of an MRI compatible Leksell stereotactic frame, MRI scans, and digital angiography of the patient's head and frame, fiducials were used for computerized targeting of recording sites. The electrodes were introduced through titanium screw guides fixed in $4.8-\mathrm{mm}$ holes drilled in the temporal or frontal bones. Earlier patients in the series were implanted with nichrome electrodes with 8 contacts. The electrodes were targeted primarily at mesial temporal structures, including the amygdala, entorhinal cortex, and presubiculum, the anterior, middle, and posterior hippocampus, and the middle and posterior parahippocampal gyrus. Extratemporal sites included the orbital frontal cortex, anterior and posterior cingulate cortex, and supplementary motor cortex. Across patients, the number of recording sites varied, but the location of the designated temporal lobe sites was always the same, allowing comparisons to be made from patient to patient. Detailed descriptions and illustrations of these temporal lobe recording sites have been previously described (Behnke, in press; Wilson et al., 1990). The choice of electrode sites was dependent upon preoperative 
scalp monitoring of spontaneous seizures, MRI and PET evidence for atrophy, hypometabolism, or other pathology, as well as seizure semiology and neuropsychological evaluation (Engel et al, 1989).
Electrode position was verified using in-situ MRI scans of the implanted electrodes. Examples of MRI scans of mesial temporal electrodes are shown in Fig. 1.
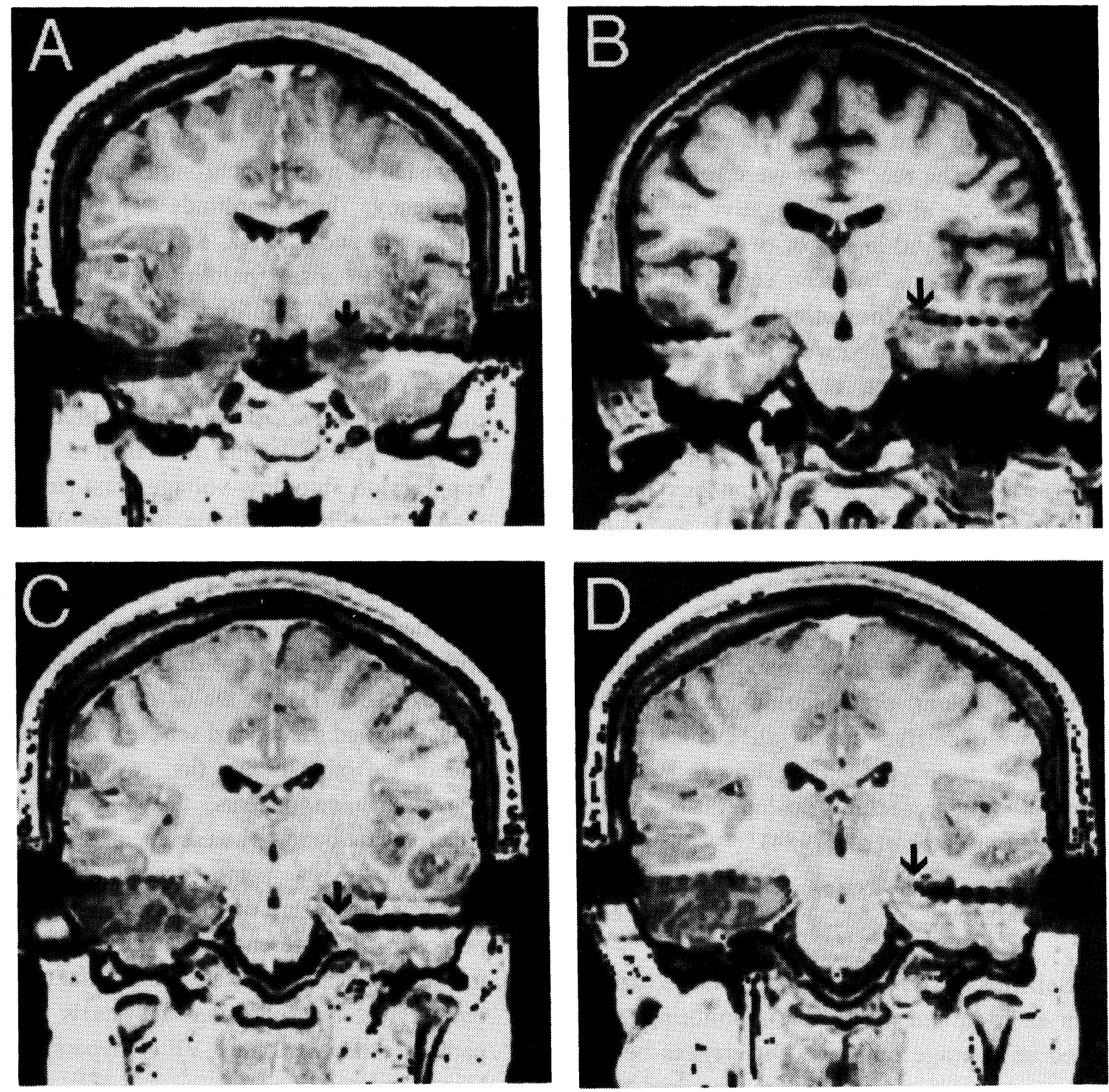

Fig. 1: Coronal MRI scans of patients at four AP levels showing mesial temporal lobe placement of depth electrodes in situ. Coronal SPGR sequences are shown at $1.0-\mathrm{mm}$ slice thickness, using a $1.5 \mathrm{~T}$ GE Signa. Platinum electrode contacts on $1.0-\mathrm{mm}$ diameter polyurethane electrodes caused signal loss that is much larger than the actual size of the electrode. Small dark areas at the tip are signal loss, due to microelectrode bundles of 9 platinum wires ( $40 \mu \mathrm{m}$ diameter) used for single neuron recordings. Loss of signal at the entry points is image artifact, due to the presence of titanium screw guides. Coronal scans are shown at the level of $A$, amygdala; B, entorhinal cortex; C, anterior hippocampus; D, posterior hippocampus. 


\section{Recording}

Seizure monitoring of EEG was carried out on a 24-h basis with either BMSI or Telefactor recording systems, using a $1.0 \mathrm{~Hz}$ low frequency cut-off and $200 \mathrm{~Hz}$ sample rate, and filtered to a high-frequency cut-off of $70 \mathrm{~Hz}$ for paper printout. EEG recording was combined with twocamera video monitoring (close-up and full body), allowing the accurate correlation of electrographic and behavioral components of ictal events. The recordings were referential to a scalp electrode at $\mathrm{Cz}$ with negative up, but were routinely displayed in one of two ways: either as bipolar derivations between sequential pairs of electrode contacts (for example, 1-2, 2-3, etc.), or as a chain montage between contact 1 of each electrode to contact 1 of the next adjacent electrode. Focal onsets were defined as those starting in one or two adjacent sites. Regional onsets were defined as simultaneous onset in three or more recording sites.

\section{Histological measures}

Cell counts in the hippocampus, dentate gyrus, subiculum, presubiculum. and entorhinal cortex were carried out in all available tissue recovered from patients who had anterior temporal lobe resections, using the techniques described by Babb et al. (1984).

\section{Data analysis}

Seizures analyzed included all those captured from each patient during the monitoring, which lasted an average of $2 \mathrm{wk}$. Differences between the means were measured with unpaired t-tests, the nonparametric Welch test, or the MannWhitney U-Test. Comparisons of the groups were evaluated using the Chi Square Test and Fisher's Exact Test of Probability. A confidence level of $p<0.05$ was required for significance.

\section{RESULTS}

Two seizure-onset patterns characterized the majority of ictal onsets that were recorded in the mesial temporal areas of this patient population. We designated the first onset pattern low-voltage fast (LVF) because the EEG was initially desynchronized, consisting of high-frequency, lowamplitude discharges over $10 \mathrm{~Hz}$. In contrast, a second seizure-onset pattern, which was encountered more frequently than the first, consisted of hypersynchronous activity with lowfrequency, high-amplitude spikes having a frequency under $2 \mathrm{~Hz}$, and lasting more than 5 sec. Both onset patterns evolved into the rhythmic, high-amplitude, paroxysmal activity commonly characterizing ictal discharge. A third onset pattern, which occurred less frequently than the first two, began with a high-amplitude spike or spikes lasting less than $5 \mathrm{sec}$ before suppression into low-voltage, fast activity that then evolved into rhythmic, high-amplitude ictus.

A total of 478 seizures were recorded from the 68 patients reviewed. The number of seizures recorded from each patient ranged from 2 to 21 , with a mean number of seizures reviewed per patient of 7.02 (SD \pm 3.71$)$. Of the 68 patients reviewed, 53 (78\%) showed stereotyped seizure onsets comprising one or the other of the first two types described above. In nine patients, the third seizure-onset pattern was found, whereas six patients exhibited LVF onsets on some occasions and hypersynchronous seizure onsets on others. Because the purpose of the present investigation is to describe the properties and correlates of the first two seizure onset types, the following analysis is devoted to patients exhibiting only LVF or hypersynchronous seizure onsets.

\section{Low-voltage fast seizure onsets}

From the 18 patients exhibiting LVF onsets, an example of a typical seizure onset is shown in Fig. 2. 

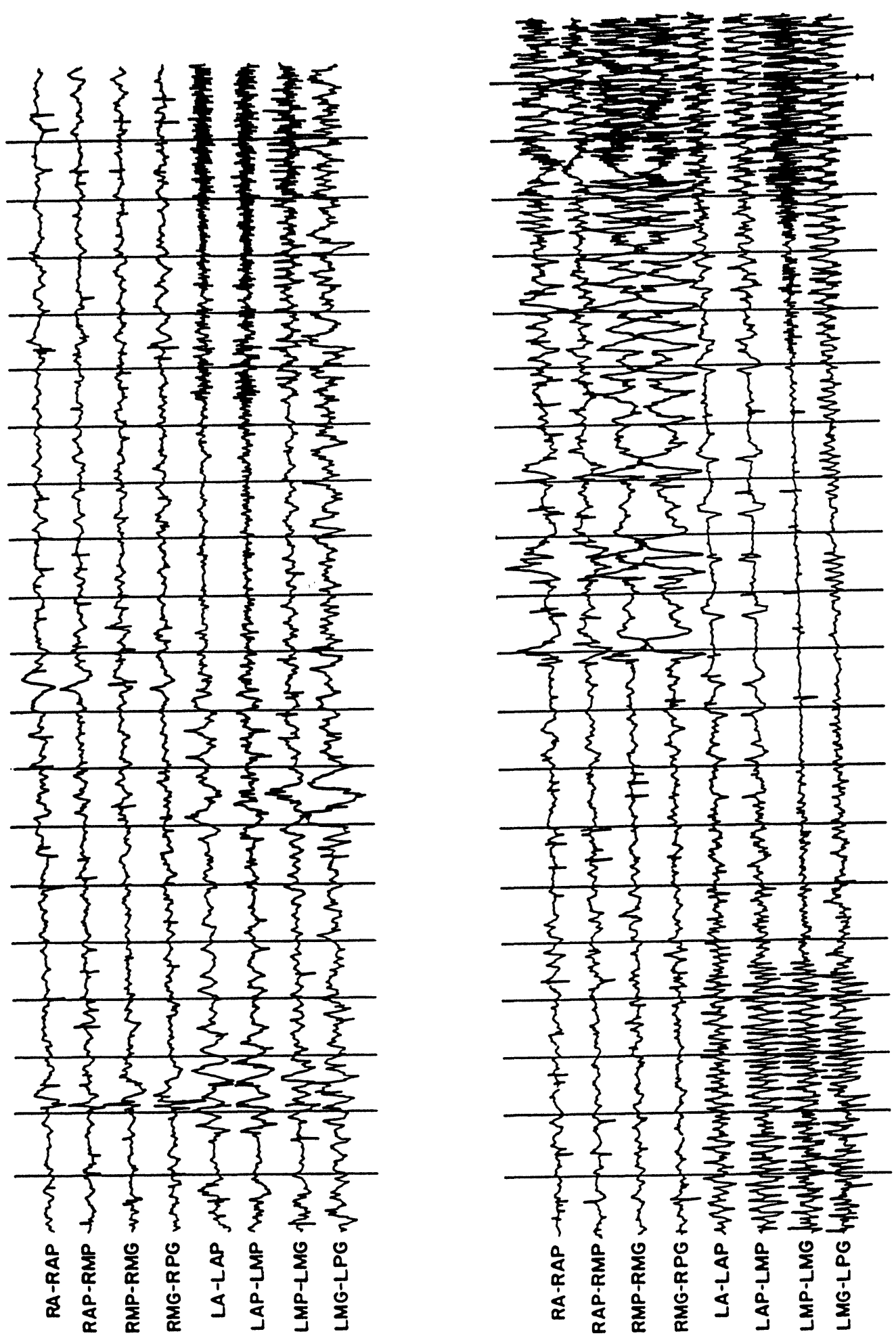

$\nsubseteq \approx$

온 힌

융

营 范

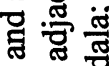

产 సี

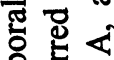

这灾

종 응

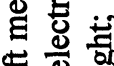

凁

넝 용

矛渮

을. 을.

过

.ヨ 은 휸을

岁造

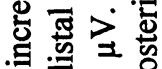

궁

蕓 О人

๑ ⿷॥

总严总

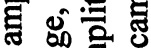

.

号 용

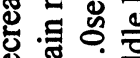

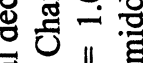

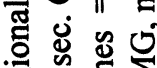

엉유

岕苋

羟

엉으응 을

늘융ㅁㅇㅁㅇ

Ф ฐ

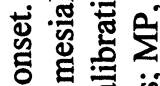

틀

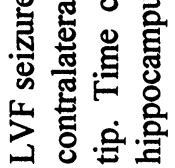

ii

舟 
In this example, left mesial temporal sites in a chain montage including amygdala, the anterior and middle hippocampus, and the middle parahippocampal gyrus displayed a highfrequency, low-amplitude pattern beginning 10 sec after the start of the EEG sample at top left. The background before the pre-ictal portion visible here was the same, with frequent spikes and waves. In the left mesial sites, the LVF activity gradually increased in amplitude until paroxysmal high-amplitude rhythmic spiking appeared. The high-amplitude, regional discharge in the left mesial structures then suppressed into a second, high-frequency, low-amplitude pattern, which was accompanied within a few seconds by spread to the contralateral mesial temporal lobe. The contralateral site then exhibited highamplitude spiking, which was followed by seizure discharge. Rapid spread to the contralateral side in the presence of an LVF discharge was a frequent observation, sometimes during an LVF onset or sometimes following a hypersynchronous onset (as seen in Fig. 4).

Figure 3 shows a second example of an LVF onset, consisting of a brief, 4-sec regional suppression containing very high-frequency activity, little of which can be resolved within the $70 \mathrm{~Hz}$ high-frequency limit of the recording equipment during the suppression. A high-frequency rhythmic recruiting discharge followed the suppression, and continued up to the break in the traces seen in the lower portion of the record. Although a high-amplitude discharge did not occur on the contralateral side, the left mesial temporal leads showed rhythmic discharge $14 \mathrm{sec}$ after the onset on the right. Concurrent with the movement artifact in left orbital frontal cortex, the patient reported that he was having a seizure, and immediately became unresponsive to verbal commands, displaying oral automatisms, chewing, and salivation. During this period, the left anterior hippocampus also showed rhythmic low-amplitude discharge, and whereas the left temporal sites showed an immediate return to baseline EEG, the right side showed a rhythmic theta/delta pattern lasting for many seconds before termination. During this period, the patient remained in a confused state. Both examples show the typical LVF seizure characteristics of regional onset and rapid spread outside of mesial temporal structures.

\section{Hypersynchronous seizure onsets}

From the 35 patients with hypersynchronous onsets, an example of a typical seizure onset is shown in Fig. 4, in which rhythmic spiking of the left presubiculum at $1.8 \mathrm{~Hz}$ was the most prominent EEG feature. This was accompanied by spiking in adjacent left mesial temporal sites, which then developed a low-amplitude, fast, recruiting pattern, which spread to the contralateral mesial temporal sites and ipsilateral temporal surface. This hypersynchronous seizure was less focal and demonstrated more rapid spread $(30 \mathrm{sec})$ than the average hypersynchronous onset.

The hypersynchronous seizure onset illustrated in Fig. 5 consisted of large amplitude focal spiking at a frequency of approximately $1.0 \mathrm{~Hz}$ in the left anterior hippocampus, which continued for $2 \mathrm{~min}$ before developing into a regional, highfrequency, high-amplitude seizure discharge expressed primarily in the left middle hippocampus. After another $10 \mathrm{sec}$, a fast, lowamplitude recruiting discharge developed in the left mesial temporal lobe, which subsequently spread to the contralateral side. The development of a high-frequency intra-ictal recruiting discharge was a frequent occurrence after a focal hypersynchronous onset became ipsilaterally regional, and seizure spread to the contralateral side usually accompanied development of these highfrequency regional discharges. Spread patterns of LVF and hypersynchronous seizures

To quantify the spread characteristics of these two seizure types and the rate of occurrence of their focal or regional onsets, the 18 patients with 

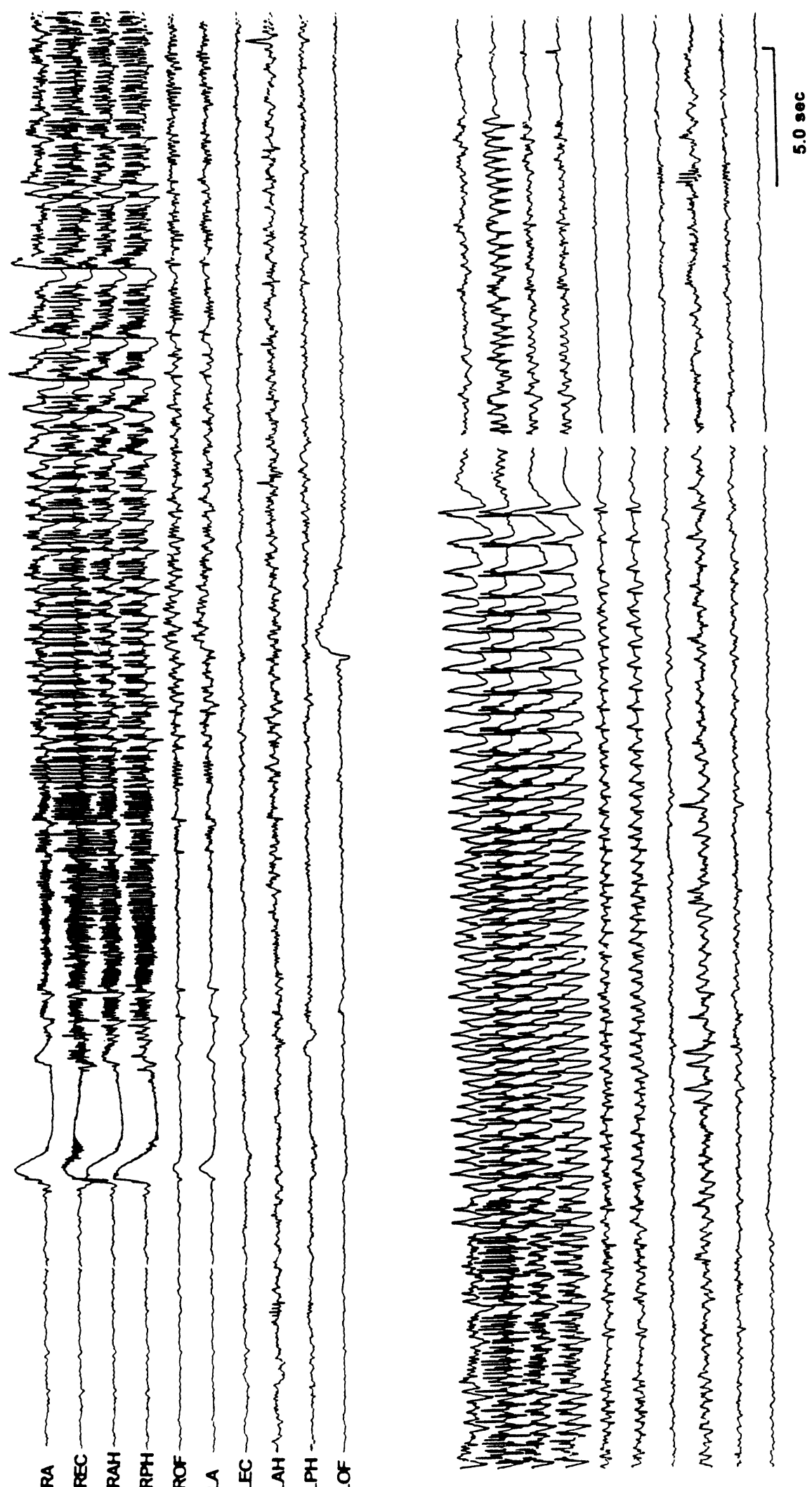

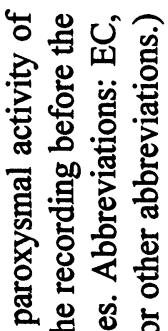

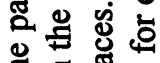

‡.

สิ

สี

娄芯起

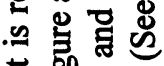

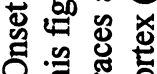

토.응 중

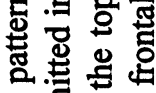

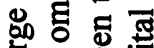

包

웡

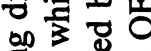

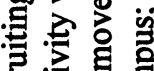

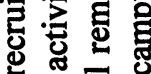

元要要

웜 올

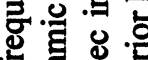

해령

灵 攺

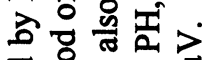

일.

은 을

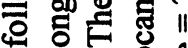

ธㅇํ응

응월을

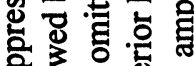

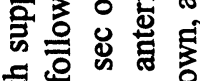

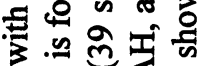

岕

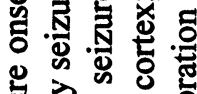

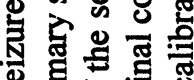

结记

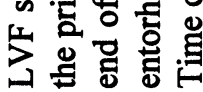

$\ddot{m}$ 

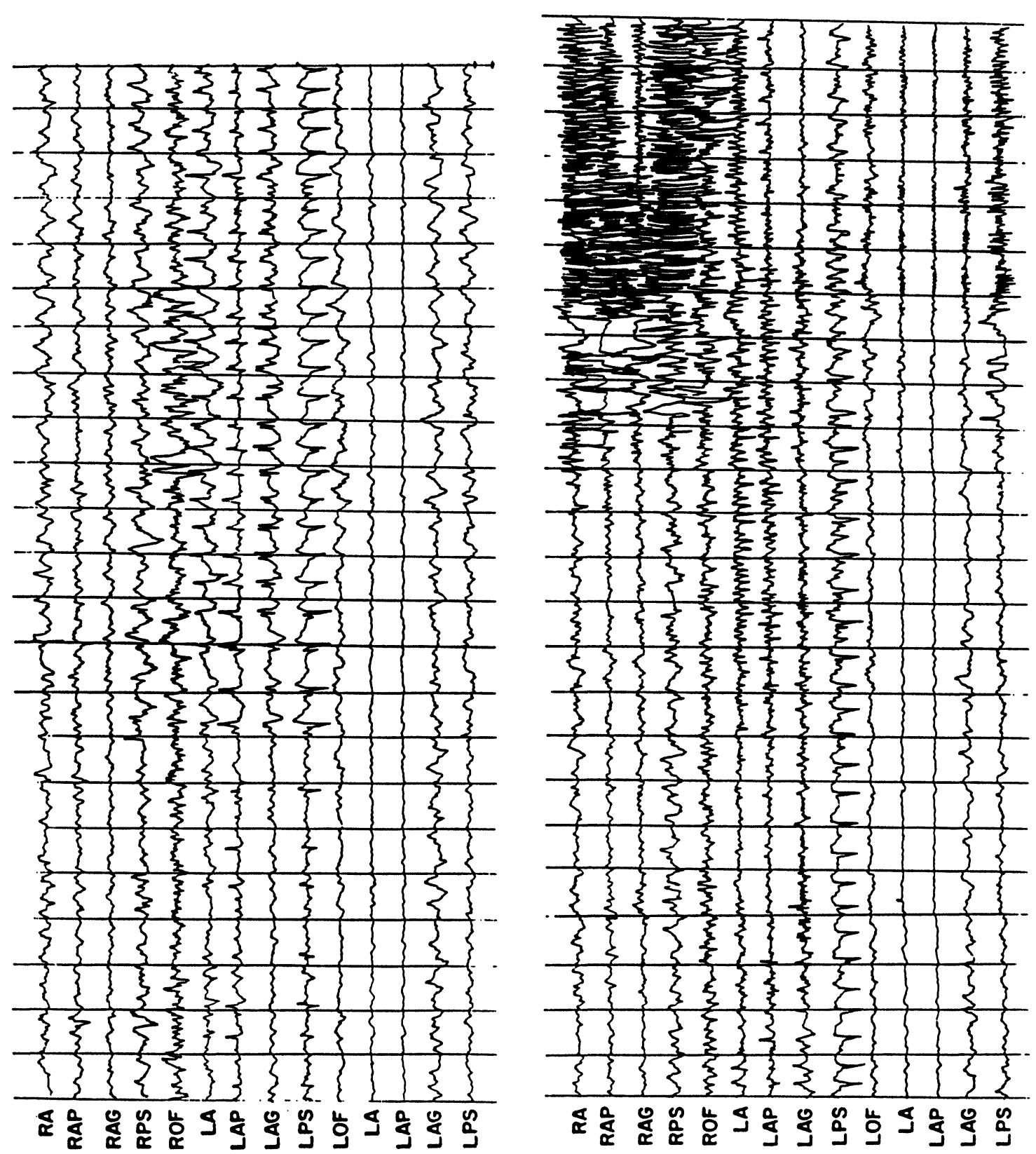

전 密官 可高 壱完㐘

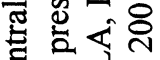

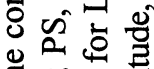
ङ क्षे

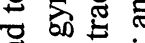
政

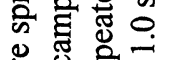
궁

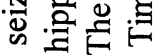

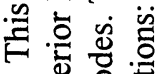
品志 矛 0 $\frac{\mathrm{d}}{0}$ 若 응 초융유 \&芯芯 音造造总 正导 ว. 공 入 $N$ 帘 क 的产 : के है क 항 $\stackrel{2}{2} \%$ 토을

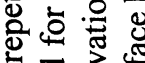

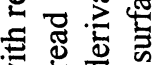
3 인 के \% 원. 궁 중 记 哭焉 की 궝 요 홍

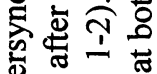
这造造 

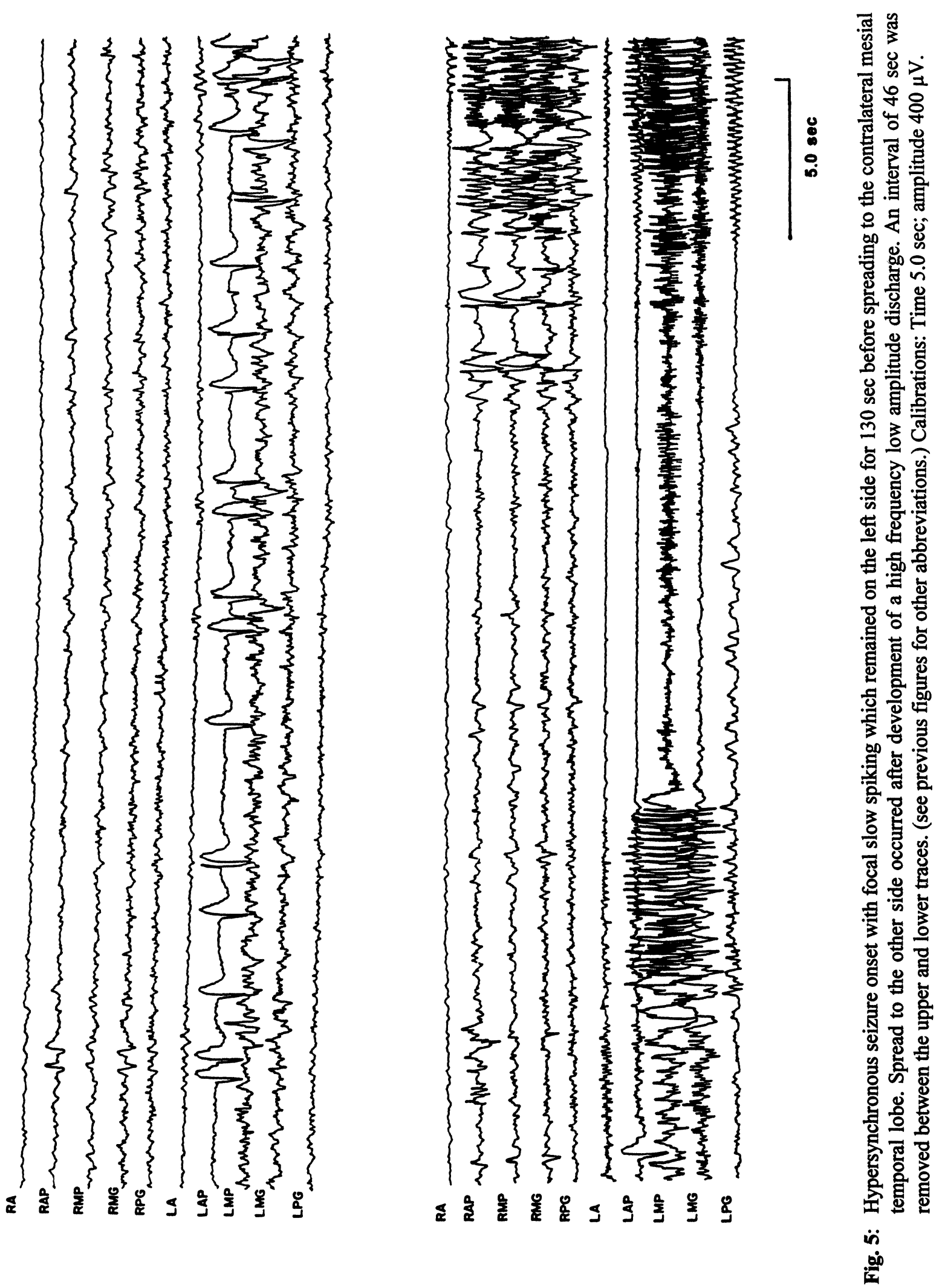
LVF onsets and 35 patients with hypersynchronous onsets were compared. As shown in Fig 6A, 17 of 18 patients with LVF seizure onsets had regional onsets, while 13 of 35 patients had regional onsets. Fisher's Exact Test (1-tail) indicates that this difference is significant at the $\mathrm{p}<.01$ level. In Fig. $6 \mathrm{~B}$, the mean time of seizure spread to the contralateral temporal lobe was calculated for each group. Seizures in patients with hypersynchronous seizure onsets required an average of $54.4(\mathrm{SEM} \pm 6.0) \mathrm{sec}$ to spread contralaterally, while seizures in patients with LVF seizure onsets required $30.1 \pm 6.0 \mathrm{sec}$ (SEM used for this and the remainder of Results). An unpaired two tailed t-test not assuming equal variance shows this difference was significant at the $p<0.003$ level.

\section{Analysis of hippocampal pathology:}

To investigate the anatomical substrate of these contrasting seizure patterns, we analyzed tissue resected from the group of patients
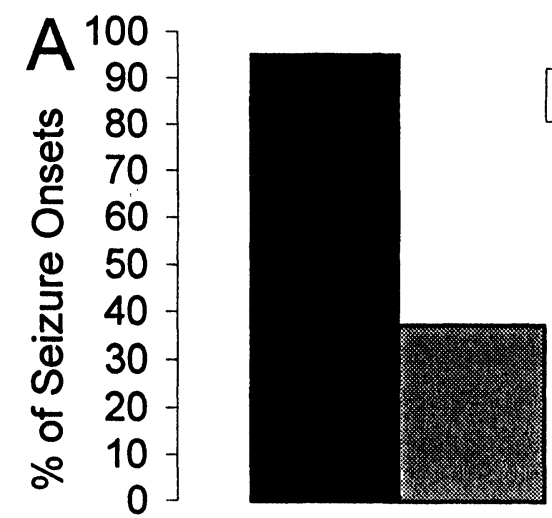

LVF Onset

\section{\%Regional [0\% \%ocal}

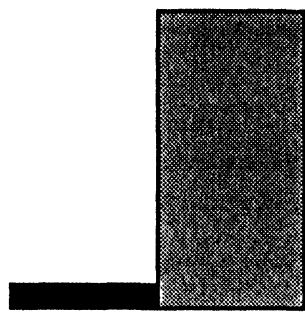

HSYNC Onset

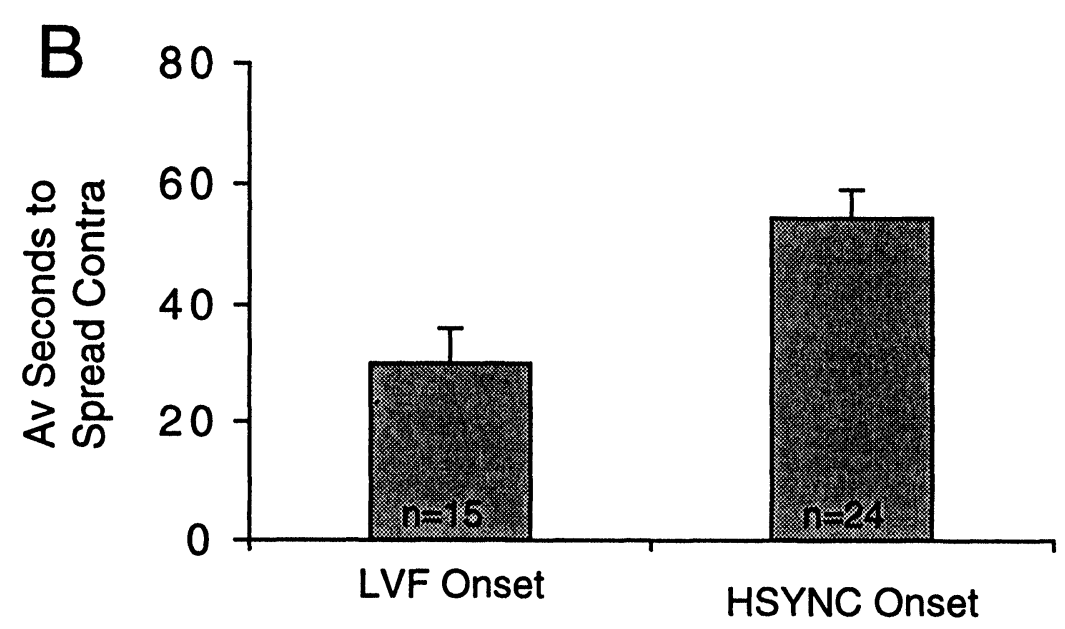

Fig. 6: A. Percentage of regional seizure onsets vs. focal seizure onsets for 18 patients with LVF seizure onset vs 35 patients with hypersynchronous (HSYNC) seizure onsets. B. Averages and \pm SEM in secs of the time required for seizure spread to the contralateral mesial temporal lobe in patients with LVF vs hypersynchronous seizure onsets. 
exhibiting LVF onsets, and those exhibiting hypersynchronous onsets who received en bloc anterior temporal lobe resections. We carried out cell counts in 14 patients with LVF onsets and 29 with hypersynchronous seizure onsets. Cell loss was expressed as a percentage of the number of cells in temporal lobe tissue from normal autopsy specimens, as described by Babb and colleagues (Babb et al., 1984).

Figure 7 shows the mean cell loss for all hippocampal fields combined in patients with LVF seizures. The mean loss in patients with LVF seizure onsets was $48.7 \%( \pm 5.2)$, whereas the mean cell loss measured in resected tissue from patients with hypersynchronous seizure onsets was $69.1 \%( \pm 1.7)$. Substantial neuronal loss occurred in both groups, but the loss was significantly greater in patients with hypersynchronous onsets (unpaired t-test with unequal variance, $p<0.001$ ). Using a criterion of $40 \%$ cell loss or greater for the diagnosis of hippocampal sclerosis (HS), $100 \%$ of patients with hypersynchronous seizure onsets showed HS, as compared with only $42.9 \%$ of patients with LVF onsets showing HS. This difference is significant at the $p<.005$ level (Fisher's Exact Test). Neuronal loss in patients having hypersynchronous onsets ranged from 45 to $97 \%$, with $79.3 \%$ of patients showing $60 \%$ or more cell loss. Neuronal loss in patients with LVF seizure onsets ranged from 0 to $87 \%$, with only $28.6 \%$ of patients showing $60 \%$ or more neuronal loss. The difference in these proportions by Fisher's Exact Test is $\mathrm{p}<0.001$.

In addition to comparisons between patients, based on all hippocampal fields combined, we analyzed the differences in the cell loss between all hippocampal fields and associated areas, and plotted the percent of cell loss in Fig. 8. Hypersynchronous mesial temporal cell loss was significantly greater than LVF in CA1, CA3, prosubiculum, and stratum granulosum of both blades of the fascia dentata, but showed no difference in CA2, subiculum, presubiculum, and parahippocampal gyrus, areas that are known to be resistant to neuronal loss in HS.

\section{DISCUSSION}

Two types of seizure onset predominated in the complex partial seizures analyzed in the present study: (1) a slow, synchronous spiking pattern, which we term "hypersynchronous", and (2) those with "LVF" onsets that recruit paroxysmal activity as the seizure develops. In the population studied, hypersynchronous onsets were found in about twice as many patients. Analysis of the variables associated with these two onset types indicates that they provide useful indicators of several characteristic $s$ of mesial temporal epilepsy. These features include (a) seizure propagation patterns and speed of seizure spread, (b) regional versus focal onset of seizures, and (c) the pathological substrates found in mesial temporal structures in which these two seizure onset types are recorded.

\section{Seizure-onset pattern and seizure propagation}

LVF seizure onsets were found to develop rapidly and spread widely to both ipsilateral and contralateral sites significantly more often than do hypersynchronous seizure onsets. Seizures beginning with hypersynchronous patterns often continued for many seconds, and sometimes minutes, in the ipsilateral mesial temporal area before spreading to adjacent or contralateral areas. In addition, seizures beginning with a hypersynchronous pattern often remained localized to the same mesial temporal area until they were over, whereas seizures beginning with an LVF pattern were more likely to propagate contralaterally. These characteristics also have been described by Spencer (1998), who attributed the lowered probability of spread to the loss of CA4 neurons that they assumed project to the contralateral hippocampus (Spencer et al., 1992b). Nonetheless, in lower primates and humans, both 


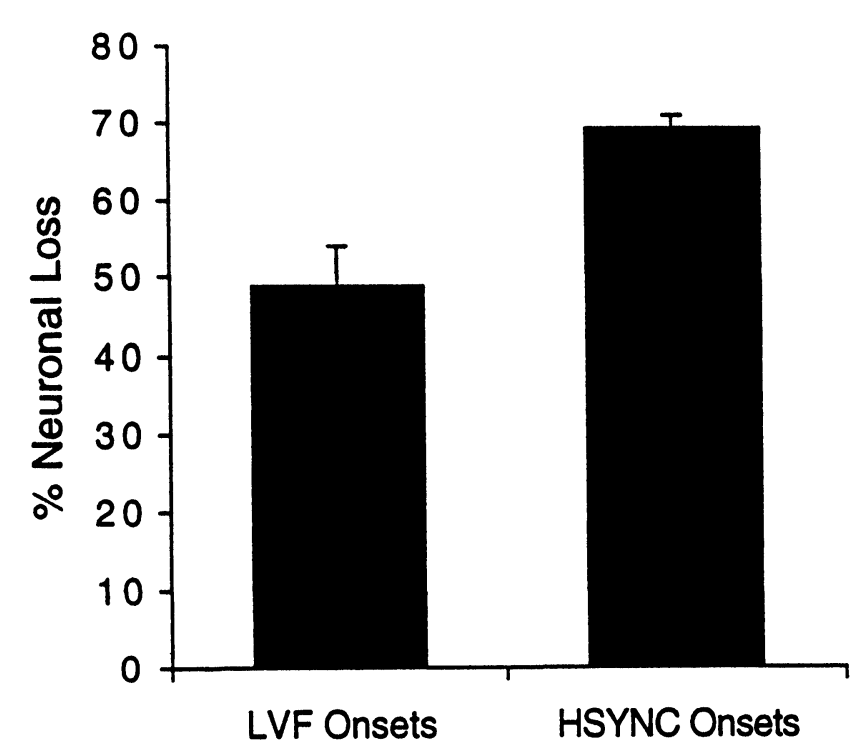

Fig. 7: Mean neuronal loss in all hippocampal fields combined of patients with hypersynchronous seizure onsets versus those with LVF onsets. The averages include cell counts from CA1, CA2, CA3, CA4, and prosubiculum.

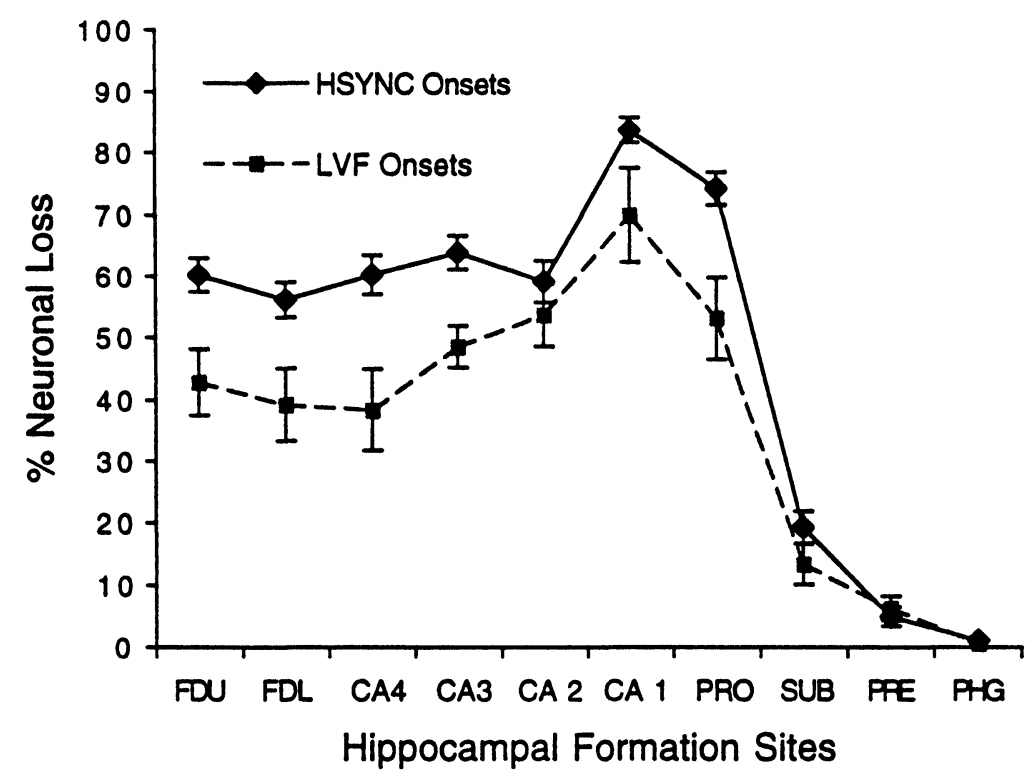

Fig. 8: Mean percentage of cell loss, LVF vs hypersynchronous seizure onsets. The mean and SEM of cell counts for all patients who came to surgery, from whom pathology analysis of resected anterior temporal lobes was obtained. Abbreviations: FDU, fascia dentata, upper blade; FDL, fascia dentata, lower blade; CA1, Cornu Ammonis 1; CA2, Cornu Ammonis 2; CA3, Cornu Ammonis 3; CA4, Cornu Ammonis 4; PRO, Prosubiculum; SUB, Subiculum; PRE, Presubiculum; PHG, Parahippocampal gyrus. A t-test showed that the significance of the difference between LVF and hypersynchronous seizure onsets was $p<0.05$ for CA1 and $\mathrm{p}<0.01$ for all other hippocampal and dentate sites, with the exception of CA2. There was no significant difference between groups for neuron loss in SUB, PRE, or PHG. 
anatomical (Gloor et al, 1993; Amaral et al., 1984; Demeter et al., 1985) and functional (Wilson et al., $1990,1991)$ evidence points to a reduced ventral hippocampal commissure, but an intact dorsal hippocampal commissure. Because the CA4 commissural projection follows the ventral hippocampal commissure (Amaral \& Insausti, 1990), the loss of CA4 neurons might not be as important as the absence of CA1 neurons, which are also greatly reduced in patients with HS (Babb \& Brown, 1987). Because neurons of the presubiculum and posterior parahippo-campal gyrus provide the vast majority of fibers forming the dorsal hippocampal commissure (Amaral et al., 1984), an alternative hypothesis explaining the lack of propagation of hyper-synchronous seizure onsets might be the loss of CA1 cells that normally send hippocampal output to presubiculum and posterior parahippocampal gyrus. An additional consideration is that the greater rapidity and frequency of LVF seizure onset spread to remote structures may be a function of more diffuse and widespread LVF onset origins, supporting the notion that the LVF pattern is one involving mesial temporal/ neocortical networks rather than local circuits limited to the hippocampal formation.

\section{Seizure-onset pattern and focal versus regional onsets}

The regional nature of LVF seizure onsets is consistent with the observations in the previous section. Rapid and frequent spread are logical concomitants of seizures that simultaneously involve multiple brain structures from their onset, as found in the present study. Such seizure onsets, which may involve neocortical participation following trauma or tumor establishment in lateral temporal cortex, may establish mesial temporal involvement via projections to the entorhinal cortex, which in turn, might incorporate the hippocampus. This involvement may be further promoted by dual pathology, in which the hippocampus is predisposed to a hypersynchronous paroxysmal discharge. When driven by seizure propagation from the neocortex, this discharge is capable of breaking down the dampening influence of the normally powerful dentate gyrus inhibition (for example, Lothman et al., 1991). Seizure onsets consisting solely of local circuit hypersynchrony may or may not have the capacity to escape from the hippocampal formation and involve adjacent or contralateral structures; therefore, hypersynchronous onsets may sometimes remain locally confined.

\section{Seizure-onset pattern and mesial temporal pathology}

The association of hypersynchronous mesial temporal onsets and HS has been known for some time (Engel, 1989; Spencer et al., 1992c; Townsend \& Engel, 1991; Spanneda et al., 1997). Hippocampal gliosis, a pathology that is usually associated with HS, has been found to be the most severe in patients with repetitive spiking at seizure onset (Park et al., 1996). The present report provides further support for these studies, and with a large patient population, provides evidence that the neuronal loss associated with hypersynchronous seizure onsets is not limited to one particular hippocampal area. When compared with patients with LVF onsets, patients with hypersynchronous seizure onsets showed a significantly greater neuronal loss in dentate hilus (CA4), upper and lower blades of dentate gyrus stratum granulosum, all hippocampal fields except $\mathrm{CA} 2$, and prosubiculum. The lack of difference in the CA2 field is not surprising, given its well known resistance to neuronal loss, even in the presence of HS (Babb \& Brown, 1987).

The presence of HS in association with hypersynchronous seizure onsets is probably not coincidental, given the results of neuropathological studies demonstrating both retention of GABAergic interneurons in human hippocampus (Babb et al., 1989) and the synaptic reorganization 
produced by the sprouting of mossy fibers in the dentate gyrus (Sutula et al., 1989; Houser et al., 1990; Babb et al., 1991). Mossy fiber recurrent excitation of granule cells or enhanced synchrony via innervation of interneurons or concomitant occurrence of both types of synaptic reorganization could contribute to the genesis of the hypersynchronous onsets observed in the present investigation. Although many studies have shown an association of mossy fiber sprouting with HS, data on mossy fiber reorganization was not available in the patient population of the present study, and further neuropathological and neurophysiological research will be required to support a causal relationship between mossy fiber sprouting and hypersynchronous seizure onsets.

The LVF recruiting seizure onset that is found in patients with less pronounced HS. or occasionally in the absence of HS, implicates the disinhibition of external multisynaptic networks in the generation of temporal lobe seizure discharge and spread to other structures. The frequent appearance of this pattern at the point of spread of an initially hypersynchronous seizure onset supports the role of this discharge pattern in the spread of seizures having either type of onset.

\section{CONCLUSIONS}

The prevalence of hypersynchronous seizure onsets in patients with temporal lobe seizures suggests that synchronization rather than disinhibition is the predominant mode of human hippocampal epileptogenesis. Although this EEG pattern is closely associated with hippocampal formation neuronal loss and HS, there is anatomical evidence for the conservation of GABAergic interneurons (Babb et al., 1989) and functional evidence for the maintenance of strong dentate gyrus inhibition (Tuff et al., 1983; Wilson et al., 1998). This evidence, and the results of the present study emphasize the need for further investigation of the role of inhibitory mechanisms in epilepsy.

\section{ACKNOWLEDGMENTS}

The authors wish to express their thanks to John Townsend, MD, and Gary Mathern, MD, for their assistance in data collection, and to Jim Pretorius, MS, in histology. Funding was provided by NIH grants NS20808 and NS33310.

\section{REFERENCES}

Amaral DG, Insausti R, Cowan WM. The commissural connections of the monkey hippocampal formation. J Comp Neurol 1984, 224:307-336.

Amaral, DG, Insausti, R. The hippocampal formation, In: Paxinos G, ed., The Human Nervous System. New York: Academic Press, 1990.

Babb TL, Brown WJ. Pathological findings in epilepsy. In: Engel J Jr, ed, Surgical Treatment of the Epilepsies. New York: Raven Press, 1987.

Babb TL, Brown WJ, Pretorius J, Davenport C, Lieb JP, Crandall PH. Temporal lobe volumetric cell densities in temporal lobe epilepsy. Epilepsia 1984; 25: 729-740.

Babb TL, Kupfer WR, Pretorius JK, Crandall PH, Levesque MF. Synaptic reorganization by mossy fibers in human epileptic fascia dentata. Neuroscience 1991; 42: 351-363.

Babb TL, Pretorius J, Kupfer WR, Crandall PH. Glutamate decarboxylase immunoreactive neurons are preserved in human epileptic hippocampus. J. Neuroscience 1989; 9: 2562-2574.

Behnke EJ, Wilson CL, Maidment NT, Fried I, Fields TA, Staba R, et al. An electrode for recording single neuron and field potential activity adapted for concurrent in vivo microdialysis in the human brain. $\mathrm{J}$ Neurosci Meth (in press).

Demeter S, Rosene DL, Van Hoesen, GW, Interhemispheric pathways of the hippocampal formation, presubiculum, entorhinal and posterior hippocampal cortices in the rhesus monkey: The structure and function of the hippocampal commissures. J Comp Neurol, 1985, 233: 30-47.

Engel J Jr. Functional explorations of the human epileptic brain and their therapeutic implications. Electroencephalogr Clin Neurophysiol 1990; 76: 296-316. 
Engel, J Jr, Babb TL, Crandall PH. Surgical treatment of epilepsy: Opportunities for research into basic mechanisms of human brain function. Acta Neurochirugica 1989; 46(Suppl): 3-8.

Gloor P, Salanova V, Olivier A, Quesney LF. The human dorsal hippocampal commissure: An anatomically identifiable and functional pathway. Brain 1993, 116: 1249-1273.

Houser CR, Miyashiro J, Swartz B, Walsh GO, Rich J, Delgado-Escueta AV. Altered patterns of dynorphin immunoreactivity suggest mossy fiber reorganization in human hippocampal epilepsy. J. Neuroscience 1990; 10: 267-282.

Lothman EW, Bertram EH, Stringer JL. Functional anatomy of hippocampal seizures. Prog. Neurobiol 1991; 37: 1-82.

Park Y, Murro A, King D, Gallagher B, Smith J, Yaghmai F. The significance of ictal depth EEG patterns in patients with temporal lobe epilepsy. Electroenceph Clin Neurophysiol 1996; 99: 412-415.

Schiller Y, Cascino G, Busacker N, Sharbrough F. Characterization and comparison of local onset and remote propagated electrographic seizures recorded with intracranial electrodes. Epilepsia 1998; 39: 380-388.

Spanneda F, Cendes F, Gotman J. Relations between EEG seizure morphology, interhemispheric spread, and mesial temporal atrophy in bitemporal epilepsy. Epilepsia 1997; 38: 13001314.

Spencer SS, Guimaraes P, Katz A, Kim J, Spencer DD. Morphological patterns of seizures recorded intracranially. Epilepsia 1992a; 33: 537-545.

Spencer SS, Marks D, Katz A, Kim J, Spencer DD. Anatomic correlates of interhippocampal seizure propagation time. Epilepsia 1992b; 33: 862-873.
Spencer SS, Kim J, Spencer DD. Ictal spikes: a marker of specific hippocampal cell loss. Electroenceph Clin Neurophysiol 1992c; 83: 104-111.

Spencer SS. Substrates of localization-related epilepsies: biologic implication of localizing findings in humans. Epilepsia 1998; 39: 114123.

Sutula T, Cascino G, Cavazos J, Parada I, RamÌrez L. Mossy fiber synaptic reorganization in the epileptic human temporal lobe. Ann Neurol 1989; 26: 321-330.

Townsend JB, Engel J Jr. Clinicopathological correlations of low voltage fast and high amplitude spike and wave mesial temporal stereoencephalographic ictal onsets. Epilepsia 1991; 32(Suppl): 3-21.

Tuff LP, Racine RJ, Adamec R. The effects of kindling on GABA-mediated inhibition in the dentate gyrus of the rat. I. Paired-pulse depression. Brain Res 1983; 277: 79-90.

Wilson CL, Isokawa-Akesson $\mathrm{M}$, Babb $\mathrm{TL}$, Crandall PH. Functional connections in the human temporal lobe: I. Analysis of limbic system pathways using neuronal activity evoked by electrical stimulation. Exper Brain Res, 1990, 82: 279-292.

Wilson $\mathrm{CL}$, Isokawa-Akesson $\mathrm{M}$, Babb $\mathrm{TL}$, Levesque, MF and Engel J Jr. Functional connections in the human temporal lobe: II. Evidence for a loss of functional linkage between contralateral limbic structures. Exper Brain Res, 1991, 85:174-187.

Wilson CL, Khan S, Isokawa M, Babb TL, Engel J Jr. Increased paired pulse inhibition and excitation in human epileptic hippocampus. Epilepsy Res 1998; 31:211-230. 

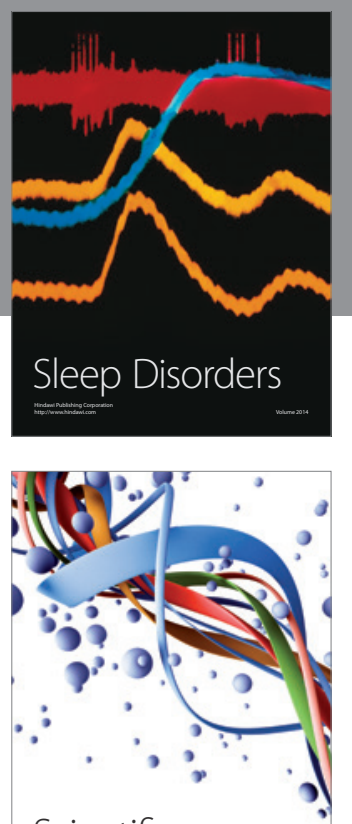

Scientifica
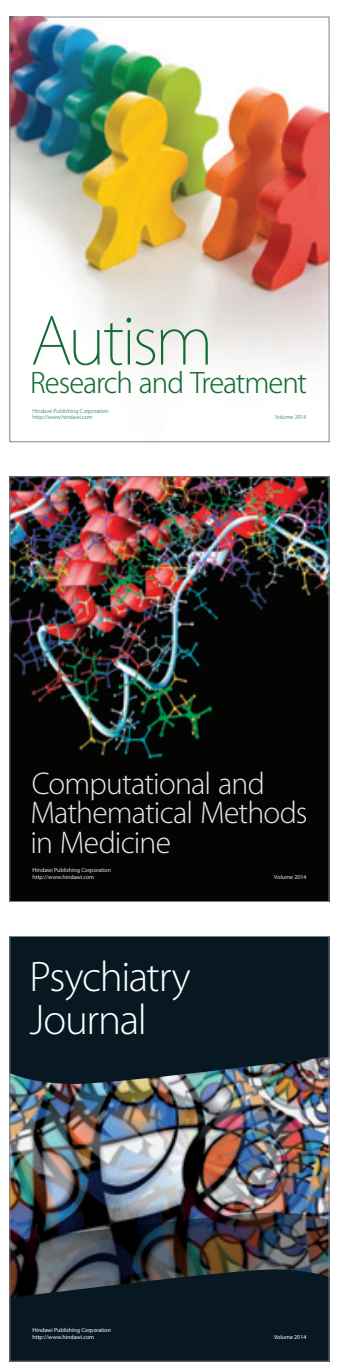
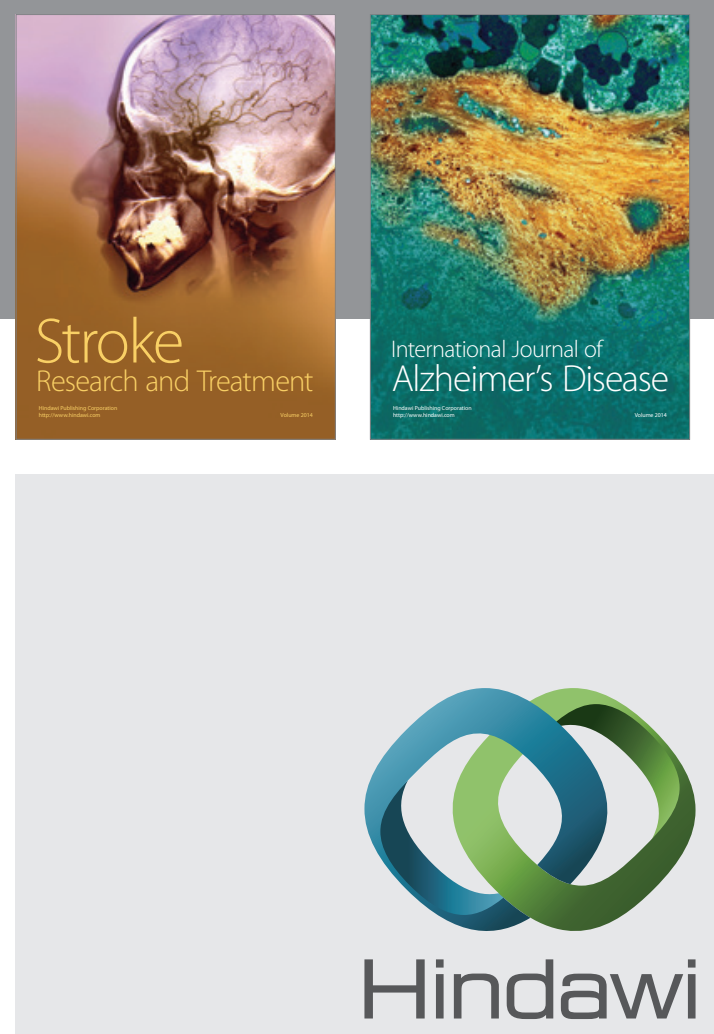

Submit your manuscripts at

http://www.hindawi.com
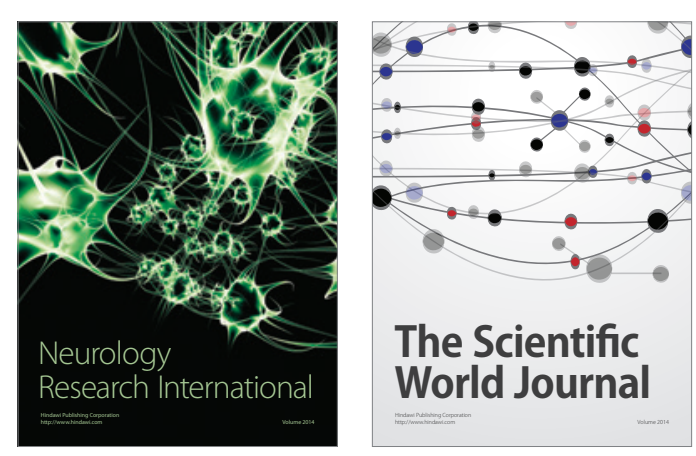

The Scientific World Journal

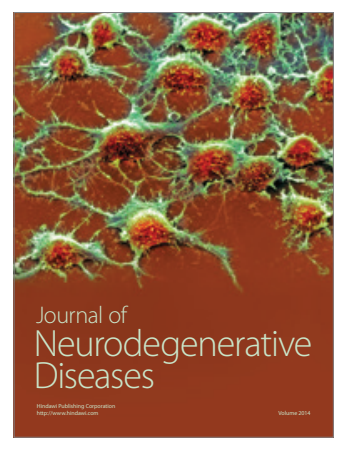

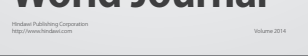

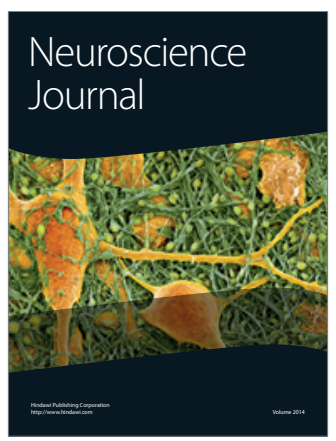

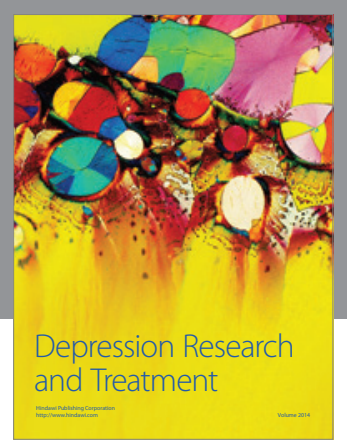
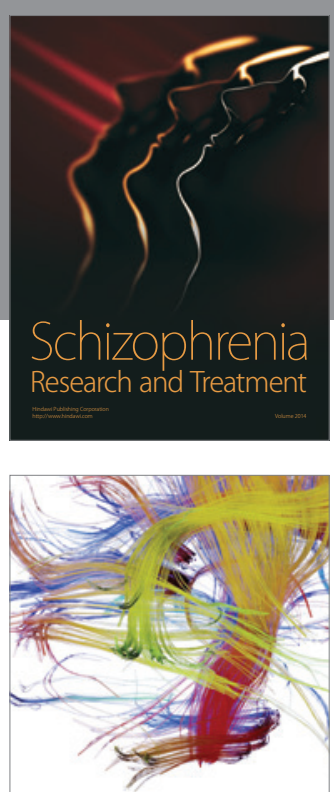

Brain Science

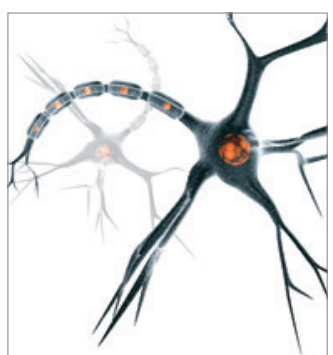

Neural Plasticity
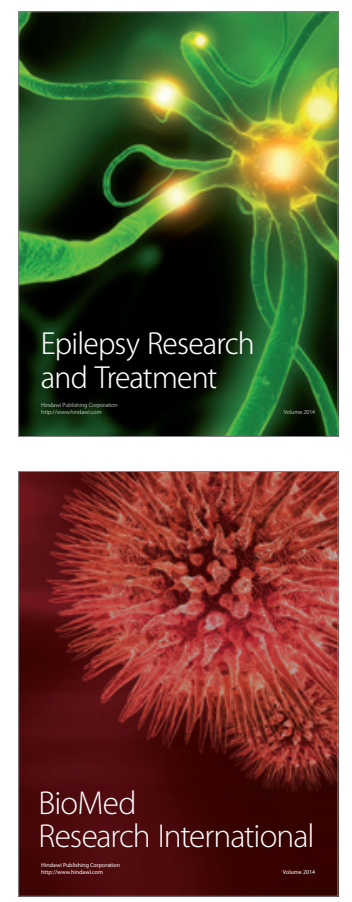

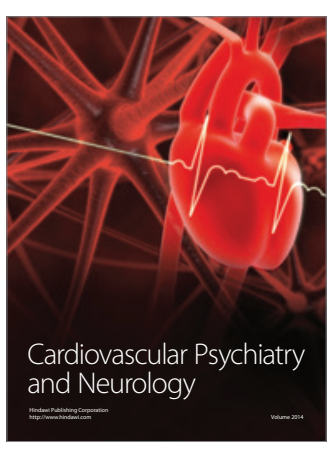

Parkinson's

Disease
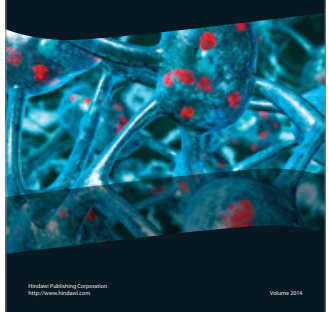